\title{
Role of CYP2C9, VKORC1 and Calumenin Genotypes in Monitoring Warfarin Therapy: An Egyptian Study
}

\author{
Naguib Zohir ${ }^{1}$, Reham Afifi ${ }^{{ }^{*}}$, Asmaa Ahmed $^{1}$, Zinab Aly $^{1}$, Mehry Elsobekey ${ }^{2}$, Heba Kareem $^{3}$, Rehab Helmy ${ }^{1}$ \\ ${ }^{1}$ Cairo University, Clinical and Chemical Pathology, 542 ElKhazan street, Cairo 24434, Egypt; ${ }^{2}$ Opthalmology Institute, \\ Opthalmology, Cairo, Egypt; ${ }^{3}$ Cairo University, Internal Medicine, Cairo, Egypt
}

\author{
Citation: Zohir N, Afifi R, Ahmed A, Aly Z, \\ Elsobekey M, Kareem H, Helmy R. Role of \\ CYP2C9, VKORC1 and Calumenin Genotypes \\ in Monitoring Warfarin Therapy: An Egyptian \\ Study. OA Maced J Med Sci. 2013 Dec 15; \\ 1(1):76-82 \\ http://dx.doi.org/10.3889/oamjms.2013.015 \\ Key words: Warfarin; VKORC1; Calumenin; \\ CYP2C9; Gene; polymorphism. \\ "Correspondence: Prof. Reham Afifi. Cairo \\ University, Clinical and Chemical Pathology, \\ 542 EIKhazan street, Cairo 24434, Egypt. E- \\ Mail: mayamahmod@ymail.com \\ Received: 13-Oct-2013; Revised: 23-Nov- \\ 2013; Accepted: 24-Nov-2013; Online first: \\ 02-Dec-2013 \\ Copyright: ๑ 2013 Zohir N. This is an open- \\ access article distributed under the terms of \\ access article distributed under the terms of \\ the Creative Commons Attribution License, \\ which permits un \\ and reproduction in any medium, provided \\ original author and source are credited. \\ Competing Interests: The authors have \\ declared that no competing interests exist.
}

\begin{abstract}
Background: Oral anticoagulant therapy is conditioned by environmental and genetic factors.

Objectives: To verify the effect of the calumenin, cytochrome P-450 variants and VKORC1 genetic polymorphisms on the response to warfarin therapy and warfarin dose adjustment.

Patients and Methods: We selected fifty warfarin treated patients with dose adjusted at INR value between 2 and 3. PCR-RFLP is used for of calumenin gene polymorphism. Insitu Hybridization was used for identification of VKORC1 promoter and CYP2C9 variants polymorphisms.

Results: The warfarin dose in the patients with Calumenin and CYP2C9 genetic polymorphism was lower than the wild type gene. The warfarin dose in the patients with VKORC1 variants was statistically lower compared to that of the wild-type. The presence of combined CYP2C9 genetic variants and VKORC1 polymorphism was associated with lower warfarin dose than that the wild types.

Conclusion: Calumenin (CALU) might be a new genetic factor involved in the pharmacogenetics of anticoagulant therapy.
\end{abstract}

\section{Introduction}

The vitamin K-dependent $\mathrm{Y}$-carboxylation system is a multicomponent system of integral membrane proteins and lipids located in the endoplasmic reticulum (ER) [1]. This system modifies vitamin K-dependent proteins post- translationally by adding an extra carboxyl group to allow calcium binding [2, 3]. In the blood coagulation system, seven proteins produced by the liver (prothrombin, factors VII, IX, and X, protein S, protein C, and protein Z) are dependent on this modification [2].

The vitamin K-dependent $\mathrm{Y}$-carboxylation system (VKOR) consists of 1) the vitamin Kdependent $Y$-carboxylase, which requires the reduced hydroquinone form of vitamin $\mathrm{K} 1$ (vit.K1H2) as cofactor, and 2) the warfarin-sensitive enzyme vitamin K1 2, 3-epoxide reductase (VKORC1), which produces the cofactor. Concomitant with $Y^{-}$ carboxylation, the hydroquinone is converted to the metabolite vitamin $\mathrm{K} 12$ 2, 3-epoxide, which is reduced back to the vit.K1H2 cofactor by VKOR [4]. This interconversion of vitamin $\mathrm{K}$ metabolites is known as the vitamin $\mathrm{K}$ cycle [3].

Warfarin is the most widely prescribed anticoagulant used for thromboembolic therapy [5]. Warfarin functions as a vitamin $\mathrm{k}$ antagonist and thus inhibits the activity of vitamin K-dependent coagulation proteins by inhibiting vitamin $\mathrm{K}$ epoxide reductase [6]. It is used for treatments of many health conditions, including arterial fibrillation, deep vein thrombosis, and recurrent stroke [7]. Large interindividual differences exist in warfarin dose requirements, which present challenges in its management. Warfarin dose requirements are influenced by ethnicity, age, gender, body mass index (BMI), and concurrent use of other medication [8]. 
In addition several studies have revealed genetic components that influence the dose of warfarin necessary for a therapeutic response.

A polymorphism within the promoter region of VKORC1 gene, encoding the subunit 1 of the vitamin $\mathrm{K}$ epoxide reductase complex; the target of warfarin, specifically a guanine to adenine conversion at position -1639 (-1639 G>A, rs9923231), decreased production of VKORC1 mRNA and reduced expression of the enzyme [9].

Cytochrome P-450 2C9 is the principle enzyme that terminates the anticoagulant effect of warfarin. Genetic polymorphisms in CYP2C9 producing variants with altered catalytic properties have been identified [10]. In addition to the wildtype CYP2C9*1 allele, 2 allelic variants, cytosine-tothymine transversion at nucleotide 430 encodes for a cysteine substitution at amino-acid residue 144 , producing the CYP2C9*2 variant allele. An adenineto-cytosine transversion at nucleotide 1075 encodes for a leucine substitution at amino-acid residue 359 , producing the CYP2C9*3 variant allele, with approximately $12 \%$ and $5 \%$ enzymatic activity, respectively, have been identified [11]. Due to an impaired metabolic capacity, patients having at least one CYP2C9*2 or CYP2C9*3 allele require, on average, a lower dose of anticoagulant than homozygotes for the CYP2C9*1 allele [12].

Calumenin (CALU) is a calcium-binding protein localized in the endoplasmic reticulum (ER) [13]. The chaperone CALU appears to regulate the capacity of the vitamin K-dependent $\mathrm{Y}$-carboxylation system [1, 14, 15]. Binding to VKOR will prevent warfarin from reaching its binding site on VKOR and thus produce resistance to the drug.

Variants in these genes affect warfarin dose requirements at steady state substantially [16, 17]; moreover, at the start of warfarin therapy, VKORC1 and, to a lesser extent, CYP2C9 genotypes also affect early INR responses [18]. The clinically useful contribution of genotype to individualizing warfarin dose will probably be greatest in the initiation phase of therapy, before a person's dose requirement has been determined empirically by titration according to INR response [19].

The US Food and Drug Administration [20] included with warfarin product labeling consideration of CYP2C9 and VKORC1 genotypes for optimizing warfarin dosing schedules. Use of genetic biomarkers could reduce the time needed to attain anticoagulation target levels, thereby reducing the incidence of adverse effects, but the optimal SNP for genotyping remain uncertain.

The main purpose of this study was to analyze genetic polymorphisms of calumenin gene (Arg4GIn), cytochrome P- 450 gene; CYP2C9*2 and *3 variants, and VKORC1 promoter gene (-1639 $\mathrm{G}>\mathrm{A}$ ) with special attention to the role of calumenin gene polymorphism (Arg4GIn) as a new marker in monitoring warfarin therapy and correlated the presence of this polymorphism together with the previously studied cytochrome P-450 gene; CYP2C9*2 and *3 variants, and VKORC1 promoter gene polymorphism $(-1639 \mathrm{G}>\mathrm{A})$ to determine if the combination between the three polymorphisms changed the required dose in patients treated with warfarin oral anticoagulant for certain indications.

\section{Subjects and Methods}

\section{Study population}

The present study was conducted on 50 patients [38 patients with valvular heart disease; mitral and tricuspid valve regurge, 6 patients with atrial fibrillation (AF) and 6 patients with deep venous thrombosis (DVT)] receiving warfarin therapy who regularly took a steady maintenance warfarin dose for at least one month provided that dose is adjusted at which INR value is between 2 and 3 . Patients who currently took oral amiodarone or anti- inflammatory agents (i.e. NSAIDs or steroid) at the time of the present study were excluded. They were enrolled from the outpatient clinic of internal medicine and cardiology at Kasr El-aini hospital, Cairo University. The age of the patients ranged from 25 to 65 years old, with a mean \pm 2 SD of $44.8 \pm 11.7$, they were 18 males (36\%) and 32 females (64\%). Their body mass index ranged from 20-24. Informed required consents were obtained from all participants in advance. The study was approved by the Scientific and Ethical Committees of Faculty of Medicine, Cairo University. Patients with hypertension, liver disease, heart failure and malignancy were excluded from the study. Routine laboratory investigations included complete blood picture, ESR, coagulation profile; prothrombin time, concentration and INR, chemistry; liver function tests, random blood sugar, lipid profile and LDH.

\section{Sampling}

Three $\mathrm{ml}$ peripheral venous blood was withdrawn in sterile vacutainer tubes containing EDTA under aseptic precautions. The samples were stored at $-20^{\circ} \mathrm{C}$ until DNA extraction.

\section{DNA extraction}

For all participants, genomic DNA was extracted from peripheral blood leucocytes using Promega Genomic DNA purification kit" (Promega Corporation, WI, USA).

Genotyping for the calumenin

CALU Arg4GIn polymorphism (rs 2290228) 
was performed by PCR using the following primers (Operon Biotechnologies $\mathrm{GmbH}$, Germany): Forward 5 -GCT TTT CAT TTT CTT CAA G- 3'(location 9192 9210) and 5- GAC CCC TGA GAG GTG GTA CC-3 (location 9485-9266), the PCR product is then digested with $\mathrm{HpyCH} 4 \mathrm{~V}$ restriction enzyme (Operon Biotechnologies).

The Arg4 allele showed a restriction pattern of 207 and 68 bp while the Gln4 allele yielded 207, 39 and $29 \mathrm{bp}$. Reaction were performed in a total volume of $25 \mu \mathrm{l}$ as Nan et al., 2001 [21] described, $12.5 \mu \mathrm{l}$ of $2 \times$ PCR Master Mix (Fermentas Life Sciences) $1 \mu \mathrm{l}$ of forward primer, $1 \mu \mathrm{l}$ reverse primers, $2 \mu \mathrm{l}$ template DNA and completed with $8.5 \mu \mathrm{l}$ water, nuclease-free. The following PCR protocol was used: initial denaturation at $95^{\circ} \mathrm{C}$ for 10 minutes, 30 cycles at $95^{\circ} \mathrm{C}$ for 45 seconds, $50^{\circ} \mathrm{C}$ for 45 seconds and $72{ }^{\circ} \mathrm{C}$ for 45 seconds and a final extension step at $72^{\circ} \mathrm{C}$ for 3 minutes.

After generation of PCR product, $\mathrm{HpyCH} 4 \mathrm{~V}$ restriction enzyme was added and incubated at $37^{\circ}$ C overnight, followed by detection of PCR amplification product by capillary electrophoresis, the bands of separation were detected using the automated QIAxcel system (Qiagen, USA) at Clinilab company, Egypt (Fig. 1)

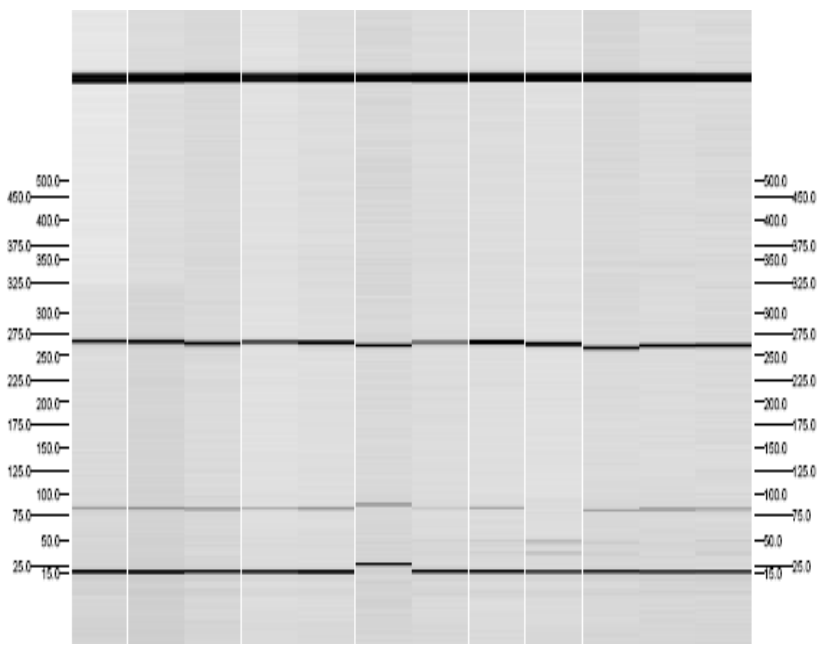

Figure 1: Results of PCR-RFLP analysis of Calumenin gene in samples from Warfarin treated patients, detected by QIAxcel instrument at Clinilab Company. The QX DNA size marker is 25-450 bp and the QX Alignment marker is 15bp/500bp. Cases No. 1, 2, 3, 4, 5, 6 and 11 have wild-type gene. Cases No. 7, 8, 10 and 12 are heterozygous for Arg4GIn polymorphism. Case No. 9 is homozygous for the polymorphism.

\section{PGX-Thrombo-strip assay}

Previously extracted genomic DNA samples were used in single multiplex $\mathrm{PCR}$ for amplification of relevant VKORC1 and CYP2C9 gene sequences, hybridization of biotinylated PCR products to oligonucleotide probes on the test strip, and finally detection of specifically bound mutant and wild-type alleles by visible enzymatic color reaction (Promega Corporation, Madison, WI USA) (Fig.2).

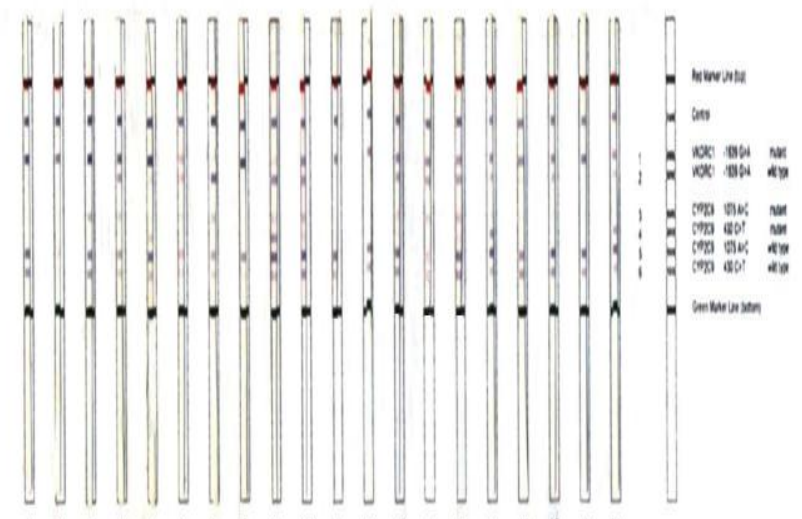

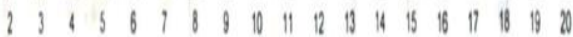

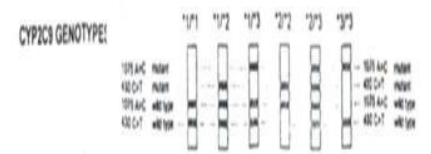

Figure 2: Results of PGX-thrombo stripassay analysis of Cyp2c9 and VKORC1 genes in samples from Warfarin treated patients. Regarding Cyp2c9 gene: cases No. 1, 6, 8, 11, 12, 17, 18 and 19 have wild-type Cyp2c9 gene; cases No. 5, 16 and 20 are heterozygous for Cyp2c9*2 allele; cases No. 3, 4, 7, 13 and 14 are heterozygous for Cyp2c9*3 allele; cases No. 9, 10 and 15 are double heterozygous for Cyp2c9*2 \& 3 alleles. Regarding VKORC1gene: case No. 7 has wild-type gene; cases No. 1, 2, 3, $5, \quad 8,11,12,17$ and 19 are homozygous for common polymorphism (-1639 G>A) in the VKORC1 promoter; cases No. $4,6,9,10,13,14,15,16,18$ and 20 are heterozygous for this polymorphism

\section{Statistical methods}

Data was analyzed using SPSS win statistical package version 17 (SPSS Inc., Chicago, IL). Numerical data were expressed as mean and standard deviation or median and range as appropriate. Qualitative data were expressed as frequency and percentage.

Chi-square test (Fisher's exact test) was used to examine the relation between qualitative variables. For quantitative data, comparison between two groups was done using Mann-Whitney test (non parametric t-test). Comparison between 3 groups was done using Kruskal-Wallis test (non-parametric ANOVA) then post-Hoc "Schefe test" on rank of variables was used for pair-wise comparison. A $p$ value $<0.05$ was considered significant.

\section{Results}

\section{Descriptive data of the patients}

The present study included 50 middle aged patients receiving warfarin therapy for valvular heart 
diseases, AF and DVT. The received doses given to adjust INR values between 2 and 3 were ranging from 2 to $20 \mathrm{mg} / \mathrm{dl}$, median $6.5 \mathrm{mg} / \mathrm{dl}$ (mean $\pm \mathrm{SD}=$ $6.95 \mathrm{mg} / \mathrm{dl} \pm 3.76$ ). The range of treatment duration was from 2.5 months to 22 years; median 10 years (mean $\pm \mathrm{SD}=10.54 \pm 6.48$ years).

\section{Genetic polymorphisms of the patients}

Results of genotyping of all patients are summarized in Table 1. No statistical significant differences could be detected between age and sex of patients with CYP2C9, Calumenin, or VKORC1genetic polymorphism and those carrying the wild types ( $p$ value for age differences = $0.946,0.373,0.769$, respectively) and ( $p$ value for sex differences $=0.869,0.233$, and 0.283, respectively).

Table 1: CYP2C, Calumenin and VKORC1 Genotypes frequency and distributions.

\begin{tabular}{|c|c|c|}
\hline Genotypes & $\begin{array}{c}\text { Frequency } \\
(\mathrm{n}=50)\end{array}$ & Percent (\%) \\
\hline \multicolumn{3}{|l|}{ CYP2C9 } \\
\hline Heterozygous $* 1 / * 2$ & 7 & 14 \\
\hline Heterozygous $* 1 / * 3$ & 11 & 22 \\
\hline Heterozygous $2 \& 3$ & 9 & 18 \\
\hline Homozygous* $1 /{ }^{*} 1$ & $\begin{array}{c}9 \\
23\end{array}$ & 46 \\
\hline \multicolumn{3}{|l|}{ Calumenin gene } \\
\hline Homozygous Glu/Glu & 3 & 6 \\
\hline Heterozygous Arg/Glu & 15 & 32 \\
\hline Homozygous Arg/Arg & 31 & 62 \\
\hline \multicolumn{3}{|l|}{ VKORC1 gene } \\
\hline Homozygous AA & 6 & 12 \\
\hline Heterozygous AG & 40 & 80 \\
\hline Homozygous GG & 4 & 8 \\
\hline \multirow{2}{*}{\multicolumn{3}{|c|}{$\begin{array}{l}\text { Combined genes } \\
\text { VKORC1 (AA,GA),CYP2C }\left({ }^{*} 2 /{ }^{*} 3,{ }^{*} 1 /{ }^{*} 2,{ }^{*} 1 /{ }^{*} 3\right) \text {, Calumenin } \\
\text { (Glu/Glu,Arg/Glu) }\end{array}$}} \\
\hline & & \\
\hline VKORC1 (AA,GA),CYP2C $\left({ }^{\star} 2 /{ }^{*} 3,{ }^{*} 1 /{ }^{*} 2,{ }^{*} 1 /{ }^{*} 3\right)$ & 14 & 18 \\
\hline VKORC1 (AA,GA), Calumenin (Glu/Glu,Arg/Glu) & 14 & 28 \\
\hline CYP2C $\left({ }^{*} 2 /{ }^{*} 3,{ }^{*} 1 /{ }^{*} 2,{ }^{*} 1 /{ }^{*} 3\right)$,Calumenin (Glu/Glu,Arg/Glu) & $\begin{array}{c}12 \\
1\end{array}$ & $\begin{array}{c}24 \\
2\end{array}$ \\
\hline
\end{tabular}

The mean warfarin doses of the patients with Calumenin genetic polymorphism was not statistically significant in comparison to patients with the wild genotype ( $p$ value $=0.135)$. However the mean maintenance doses in patients with Calumenin gene polymorphism was $82.2 \%$ of that in wild-type gene.

The mean maintenance doses in patients with CYP2C9 variant alleles was $78 \%$ of that in wild- type patients and this difference was almost statistically significant ( $p$ value $=0.050$ ).

The mean maintenance doses in patients with VKORC1 (AA, GA) polymorphism was $67 \%$ of that in wild-type, and this difference was statistically significant ( $p$ value $=0.044)$.

The present study revealed that the presence of combined CYP2C9 genetic variants and VKORC1 polymorphism (-1639 G>A) was associated with lower warfarin dose than the wild types. The mean dose for the combined CYP2C9 variants and VKORC1 (GA and AA) polymorphisms was $6.13 \mathrm{mg} / \mathrm{dl} \pm 4$ comparing to $7.83 \mathrm{mg} / \mathrm{dl} \pm 3.35$, which is $78.2 \%$ of the wild types, and this difference was statistically significant ( $p$ value $=0.042)$.

The mean dose of warfarin in patients with the combined 3 genetic polymorphisms was 4.89 $\mathrm{mg} / \mathrm{dl} \pm 3.3$, while in patients with wild type genes the mean dose was $10 \mathrm{mg} / \mathrm{dl} \pm 1$. Despite, significant relationship between the 3 polymorphisms couldn't be detected due to small number of samples within the groups; however the mean of warfarin dose in cases of combined 3 polymorphisms is lower than the mean dose for the combined wild types. The mean maintenance dose in patients with the polymorphic genes was $48.9 \%$ of those carrying wild type genes (Table 2).

Table 2: Comparison between wild and polymorphic variants of CYP2C, Calumenin and VKORC1 Genes regarding demographic data and warfarin dose and duration.

\begin{tabular}{|c|c|c|c|c|}
\hline Polymorphism & $\begin{array}{c}\text { Age } \\
(\text { Mean } \pm S D)\end{array}$ & $\begin{array}{c}\text { Sex } \\
(\mathrm{M}: \mathrm{F} \%)\end{array}$ & $\begin{array}{l}\text { Warfarine duration } \\
\text { (Mean } \pm \text { SD) }\end{array}$ & $\begin{array}{l}\text { Warfarine dose } \\
\text { (Mean } \pm \text { SD) }\end{array}$ \\
\hline \multicolumn{5}{|l|}{ CYP2C9 } \\
\hline Wild & $44.7 \pm 11.7$ & $44.4: 46.9$ & $8.79 \pm 5.63$ & $7.85 \pm 3.43$ \\
\hline Polymorphic & $44.8 \pm 11.7$ & $55.6: 53.1$ & $12.03 \pm 6.88$ & $6.19 \pm 3.93$ \\
\hline P-value & 0.946 & 0.869 & 0.079 & 0.05 \\
\hline Significance & NS & NS & NS & S \\
\hline \multicolumn{5}{|l|}{ VKORC1 } \\
\hline Wild & $42.8 \pm 6.1$ & $0: 12.5$ & $13.25 \pm 5.68$ & $9.38 \pm 1.49$ \\
\hline Polymorphic & $44.9 \pm 12.1$ & $10.0: 87.5$ & $10.30 \pm 6.55$ & $6.24 \pm 3.83$ \\
\hline P-value & 0.769 & 0.283 & 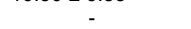 & 0.044 \\
\hline Significance & NS & NS & - & $S$ \\
\hline \multicolumn{5}{|l|}{ Caluminine } \\
\hline Wild & $43.6 \pm 11.2$ & $50: 68.8$ & $10.58 \pm 6.53$ & $7.45 \pm 3.76$ \\
\hline Polymorphic & $46.6 \pm 12.6$ & $50: 32.2$ & $10.47 \pm 6.57$ & $6.13 \pm 3.71$ \\
\hline P-value & 0.373 & 0.233 & 0.976 & 0.135 \\
\hline Significant & NS & NS & NS & NS \\
\hline \multicolumn{5}{|c|}{ Combined 3 genes } \\
\hline Wild & & & $12.67 \pm 6.81$ & $10 \pm 1$ \\
\hline Polymorphic & & & $11.89 \pm 6.81$ & $4.89 \pm 3.3$ \\
\hline P-value & & & & \\
\hline Significance & & & - & - \\
\hline
\end{tabular}

Warfarin intake duration in the patients with Calumenin genetic polymorphism mean was 10.47 years \pm 6.57 , while in those with wild type gene was 10.58 years \pm 6.53 . This differences was not statistically significant ( $p$ value $=0.976$ )

Time to therapeutic INR was longer in CYP2C9 variant * 2 and ${ }^{*} 3$ alleles carrier patients compared to those with wild-type, and longer in patients with the VKORC1 (position -1639) GG genotype (wild type) compared with those with the GA genotype and the AA genotype, however, there was no statistical significant difference between duration of warfarin intake and polymorphic CYP2C and VKORC1 genotypes ( $p$ value $=0.079$, 0.98 , respectively).

\section{Discussion}

Although no statistical significant difference was found regarding Calumenin (CALU) genotyping in the present study; the mean warfarin maintenance doses in patients with gene polymorphism was $82.2 \%$ of that in wild-type polymorphism. Similar to our results, Gonzalez-Conejero et al., 2007 genotyped 100 patients from Murcia, Spain for CYP2C*9, VKORC1 and CALU Arg4GIn polymorphism. They 
identified a homozygous CALU (GIn/GIn) patient; this patient reached a steady anticoagulation state with a low dose of oral anticoagulant [22].

On contrary to our results, Vecsler et al., 2006 found one homozygous CALU (GIn/GIn) patient required a very high warfarin dose to achieve a steady INR (20 mg/ day) [16].

On other hand, Wadelius et al., 2007 failed to find any significant association between CALU Arg4GIn and warfarin dose requirements [23].

The present study revealed that the mean warfarin dose was lower in patients with CYP2C9 genetic variants $(6.19 \mathrm{mg} / \mathrm{dl} \pm 3.93)$ than the mean in the wild type $(7.85 \mathrm{mg} / \mathrm{dl} \pm 3.43)$, with mean maintenance doses in patients with variant alleles was $78 \%$ of that in wild-type patients and this difference was almost statistically significant with a $p$ value $=0.050$.

Our results were parallel to that of Hermida et al., 2002 in Spain, they stated that bearing the $2 \mathrm{C} 9 * 2$ allele or the $2 \mathrm{C} 9 * 3$ allele was associated with the need for a lower acenocoumarol dose (odds ratio [OR], 2.70, 6.02; 95\% confidence interval [Cl], 1.11-6.58, 1.50-24.18, respectively) [24]. Our results also were in agreement to Taube. et al., 2000 [25] and Kamali et al.,2004 who demonstrated that the mean warfarin daily dose requirement in milligrams fell from $4.06 \pm 1.72 \mathrm{mg}$ in homozygous CYP2C9 wild-type patients to $3.63 \pm 1.78 \mathrm{mg}$ for ${ }^{*} 1 /{ }^{*} 2$-positive patients and $2.701 .36 \mathrm{mg}$ for ${ }^{*} 1 /{ }^{*} 3$ positive patients [26].

Ozer et al., 2010 reported that the mean warfarin daily dose requirement was higher in CYP2C9 homozygous wild-type patients, compared to those with the variant ${ }^{*} 3$ allele $(P<0.05)$, similar to those with the variant ${ }^{*} 2$ allele $(P>0.05)$ [27]. These results are also inconsistent with Sconce et al., 2005 [28] and Miao et al., 2007, who stated that CYP2C $9 * 1 / * 1$ genotypes required a significantly higher warfarin dose than those with the -1639 AA $(P$ $<0.001)$ or CYP2C9*1/*3 $(\mathrm{P}<0.001)$, genotype [29]. Carlquist et al., 2006, also detected that warfarin doses varied by CYP2C9 genotype: with dose reductions of $18-31 \%$ for single and $82 \%$ for double variant carriers $(P<0.001)[30]$.

Regarding VKORC1 gene; the mean warfarin dose in the patients with VKORC1 (AA, GA) was lower $(6.24 \mathrm{mg} / \mathrm{dl} \pm 3.83)$, than the mean warfarin dose with VKORC1 GG genotype (9.38 mg/dl \pm 1.49). The mean maintenance doses in patients with (AA, GA) polymorphisms was $67 \%$ of that in wild-type GG polymorphism, and this difference was statistically significant ( $p$ value $=0.044$ ). In heterozygous group it was $7.25 \mathrm{mg} / \mathrm{dl} \pm 3.82$ and this differences was statistically significant with $P$ value $=0.014$.

Our study was in agreement to studies done by Yuan et al., 2005, Lee et al., 2006, Kimura et al.,
2007 and Wang et al., 2008 who all reported that the 1639AA or 1173TT genotype of VKORC1 were consistently associated with lower warfarin dose requirements [9, 31-33]. Also the study by Wang et al., 2008 strongly favored 1639GA over 1173CT as the active polymorphism and that for optimal use of VKORC1 as a clinical biomarker for warfarin dose predictions, the 1639GA alone is sufficient [9].

Ozer et al., 2010 Carlquist et al., 2006, and Sconce et al., 2005, stated that the mean warfarin daily dose requirement was highest in patients with the VKORC1 -1639 GG genotype compared to those with the GA genotype and the AA genotype [27, 28, 30].

The present study revealed that the mean warfarin dose in cases of combined 3 polymrphisms (4.82 \pm 3.3) was lower than the mean dose for the combined wild types $(10 \pm 1)$. The mean maintenance dose in patients with the polymorphic gene was $48.9 \%$ of the wild type genes.

Concomitant to our results, GonzalezConejero et al., 2007 detected that carriers of the combined 3 polymorphic alleles were significantly more sensitive to therapy and they needed lower doses to stabilize their INR [22]. On the contrary, the study of Vecsler et al., 2006 revealed that CYP2C9 andVKORC1 wild type and CALU mutant patients required the highest warfarin doses as compared to the CYP2C9 and VKORC1 mutant and CALU wild type genotypes. However compound genetic profiles comprising VKORC1, CALU and CYP2C9 improve categorization of individual warfarin dose requirements in more than $25 \%$ of patients at steadystate anticoagulation [16].

The present study revealed no association between age $(r=-0.270 ; P=0.056)$ and $\operatorname{sex}(P=0.1)$ of the patients and warfarin dose requirements. In agreement with our results, Hermida et al., 2002, analyzed the effect of $2 \mathrm{C} 9^{\star} 3$ and $2 \mathrm{C} 9^{\star} 2$ variants, age, sex, and interacting drugs by using a multivariate ordered logistic regression model and detected that neither sex nor age affected the acenocoumarol anticoagulant requirement [24].

On the contrary, Sconce et al., 2005 demonstrated that median warfarin daily dose requirements varied significantly with sex $(2.9 \mathrm{mg}$ females; $3.7 \mathrm{mg}$, males; $\mathrm{P}=.009)$. The warfarin doses was negatively correlated with age $(r=0.40 ; P$ $=0.001$ ) [28].

Also, Kamali et al., 2004 demonstrated that the multiple linear regression model for warfarin dose indicated significant contributions of age $(r=0.41, P$ $<.001)$, genotype $(r=0.24, P<.005)$, and age and genotype together $(r=0.45, P<.005)$ [26].

Similarly, Aquilante et al., 2006 and Oner Ozgon et al., 2008, stated that the variables associated with lower warfarin dose requirements 
included increasing age $(P<0.0001)[34,35]$.

The present study confirmed an association between CYP2C9 variants ( ${ }^{*} 2,{ }^{*} 3$ ), VKORC1 (AA and GA) and CALU Arg/Gln polymorphisms and warfarin sensitivity, as the presence of one of this variant or 2 of them or the combined 3 genetic profiles comprising VKORC1, CALU and CYP2C9 improve categorization of individual warfarin dose requirements in patients at steady state anticoagulation. Also our results suggest that CALU a29809g might be a new genetic factor involved in the pharmacogenetics of anticoagulant therapy, although we didn't find a significant relation so we try to enlarge our studies on calumenin polymorphism.

The major complication of long-term oral anticoagulant is over-anticoagulation and bleeding. The risk of bleeding is associated with increasing INR and so identification of genetic and environmental factors that predict the development of a high INR might identify high-risk patients who would be candidates for more frequent monitoring or treatment with an alternative drug. As the pharmogenomics of warfarin-drug interactions is unraveled, genetic analysis may yet prove to have a role in the assessment of risk and management decisions relating to type of Anticoagulant, frequency of monitoring, and optimum duration of therapy.

The main limitation of our study is the relatively reduced sample size. Confirmatory studies including large series of patients are necessary, where more complex profiles may also be evaluated in order to make oral anticoagulation a personalized therapy.

\section{Acknowledgement}

We thank Dr. Rehab Helmy Mohamed MD, and our patients for their willing participation in our research. Also we thank our Cairo University for valuable participation in funding of our research.

\section{References}

1. Wallin R, Hutson SM, Cain D, Sweatt A, Sane DC. A molecular mechanism for genetic warfarin resistance in the rat. Faseb J. 2001; 15:2542-2544.

2. Furie $B$, Furie $B C$. Mechanisms of thrombus formation. $N$ Engl J Med. 2008; 359(9):938-949.

3. Suttie JW. Vitamin K-dependent carboxylase. Annu Rev Biochem. 1985;54:459-77.

4. Cain D, Hutson SM, Wallin R. J Biol Chem.1998; 273, 49824989

5. Smith $\mathrm{P}$, Arnesen $\mathrm{H}$, Holmel. The effect of warfarin on mortality and reinfarction after myocardial infarction. $\mathrm{N}$ Engi $\mathrm{J}$ Med. 1990; 323:147-152

6. Berkner KL. The vitamin K dependent carboxylase. J Nutr 2000, 130:1877-80.

7. Daly AK, King BP. Pharmacogenetics of oral anticoagulants.
Pharmacogenetics. 2003; 13:247-252.

8. Wadelius $\mathrm{M}$, Sorlin $\mathrm{K}$, Wallerman $\mathrm{O}$, Karlsson J, Yue QY, Magnusson PK, Wadelius C, Melhus $H$. Warfarin sensitivity related to CYP2C9, CYP3A5, ABCB1 (MDR1) and other factors. Pharmacogenomics J. 2004; 4:40-48.

9. Wang $\mathrm{D}$, Chen $\mathrm{H}$, Momary KM, Cavallari LH, Johnson JA, Sadée $\mathrm{W}$. Regulatory polymorphism in vitamin $\mathrm{K}$ epoxide reductase complex subunit 1 (VKORC1) affects gene expression and warfarin dose requirement. Blood. 2008; 112(4):1013-1021.

10. Strubbins M, Harries L, Smith G, Tarbit M, Wolf C. Genetic analysis of the human cytochrome P450 CYP2C9 locus. Pharmacogenetics. 1996; 6:429.

11. Schwarz UI. Clinical relevance of genetic polymorphisms in the human CYP2C9 gene. Eur J Clin Invest. 2003; 33(Suppl 2): 23-30.

12. Aithal G, Day C, Kesteven P, Daly A. Association of polymorphisms in the cytochrtomeP450 CYP2C9 with warfarin dose requirement and risk of bleeding complications. Lancet. 1999; 353:717.

13. Voora D, Eby C, Linder MW, et al. Prospective dosing of warfarin based on cytochrome P 4502 C9 genotype. Thromb Haemost. 2005; 93(4): 700-705.

14. Wajih N, Sane DC, Hutson SM, Wallin R The inhibitory effect of calumenin on the vitamin K-dependent gamma-carboxylation system. Characterization of the system in normal and warfarinresistant rats. J Biol Chem. 2004; 279:25276-25283.

15. Kollers S. Confirmation of the mapping of the porcine Calumenin gene (CALU) to chromosome 18. Anim Genet. 2005; 36: $177-178$

16. Vecsler M, Loebstein R, Almog S, Kurnit D, Goldman B, Halkin $H$, Gak E. Combined genetic profiles of components and regulators of the vitamin k-dependent gamma-carboxylation system affect individual sensitivity to warfarin. Thromb Haemost. 2006; 95:205-211.

17. G a g e BF, Birman-Deych E, Radford MJ, Nilasena DS, Binder $E F$. Risk of osteoporotic fracture in elderly patients taking warfarin: results from the National Registry of Atrial Fibrillation 2. Arch Intern Med. 2006; 166(2):241-6.

18. Schwarz UI, Ritchie MD, Bradford Y, et al. Genetic determinants of response to warfarin during initial anticoagulation. N Engl J Med. 2008; 358:999-1008.

19. Millican EA, Lenzini PA, Milligan PE, et al. Genetic-based dosing in orthopedic patients beginning warfarin therapy. Blood. 2007; 110:1511-1515

20. FDA approves updated warfarin (Coumadin) prescribing information. Press release of the Food and Drug Administration, Rockville, MD, 2007. http://www.fda.gov/bbs/topics/NEWS/2007/NEW01684.html. Accessed May 19, 2008.

21. Nan S, Wen T, Deyin X, Dongxin L. CYP1A1 polymorphism and risk of lung cancer in relation to tobacco smoking, the case control study in China" Departement of etiology, Carcinogenesis, Cancer institute, Chinese academy of medical science, Peking union medical college, Peijing 100021, China. 2001; 22(1):11- 16.

22. González-Conejero R., Corral J., Roldán V., Ferrer F., Sánchez-Serrano I., Sánchez-Blanco J.J., Marín F. and Vicente V. The genetic interaction between VKORC1 c1173t and calumenin a29809g modulates the anticoagulant response of acenocoumarol. J Thromb Haemosta. 2007; 5: 1701-1706.

23. Wadelius M, Pirmohamed M. Pharmacogenetics of warfarin: current status and future challenges. Pharmacogenomics J. 2007; 7: 99-111.

24. Hermida J, Zarza J, Alberca I, Montes R, López ML, Molina E, Rocha E. Differential effects of $2 \mathrm{C9} * 3$ and $2 \mathrm{C9} 2$ variants of cytochrome P-450 CYP2C9 on sensitivity to acenocoumarol. Blood. 2002 99: 4237-4239. 
25. Taube J, Halsal D, Baglin T. Influence of cytochrome P-450 CYP2C9 polymorphisms on warfarin sensitivity and risk of overanticoagulation in patients on long-term treatment. Blood. 2000; 96: 1816-1819.

26. Kamali F, Khan TI, King BP, Frearson R, Kesteven P, Wood P, Daly AK, Wynne H. Contribution of age, body size, and CYP2C9 genotype to anticoagulant response to warfarin. Clinical Pharmacology \& Therapeutics. 2004; 75, 204-212.

27. Ozer N, Cam N, Tangurek B, Ozer S, Uyarel H, Oz D, Guney MR and CiloGln F. The impact of CYP2C9 and VKORC1 genetic polymorphism and patient characteristics upon warfarin dose requirements in an adult Turkish population. Heart Vessels. 2010 25(2):155-62.

28. Sconce EA, Khan TI, Wynne HA, et al. The impact of CYP2C9 and VKORC1 genetic polymorphism and patient characteristics upon warfarin dose requirements: proposal for a new dosing regimen. Blood. 2005; 106:2329-2333.

29. Miao L, Yang J, Huang $C$ and Shen Z. Contribution of age, body weight, and CYP2C9 and VKORC1 genotype to the anticoagulant response to warfarin: proposal for a new dosing regimen in Chinese patients. Eur J Clin Pharmacol. 2007; 63(12):1135-41.

30. Carlquist JF, Horne BD, Muhlestein JB, Lappé DL, Whiting BM, Kolek MJ, Clarke JL, James BC and Anderson JL. Genotypes of the cytochrome p450 isoform, CYP2C9, and the vitamin $\mathrm{K}$ epoxide reductase complex subunit 1 conjointly determine stable warfarin dose: a prospective study. J Thromb Thrombolysis. 2006; 22(3):191-7.

31. Yuan HY, Chen JJ, Lee MT, et al. A novel functional VKORC1 promoter polymorphism is associated with inter-individual and interethnic differences in warfarin sensitivity. Hum Mol Genet. 2005; 14:1745-1751.

32. Lee SC, Ng SS, Oldenburg J, et al. Interethnic variability of warfarin maintenance requirement is explained by VKORC1 genotype in an Asian population. Clin Pharmacol Ther. 2006; 79:197-205

33. Kimura R, Miyashita K, Kokubo Y, et al. Genotypes of vitamin K epoxide reductase, gammaGIntamyl carboxylase, and cytochrome P450 2C9 as determinants of daily warfarin dose in Japanese patients. Thromb Res. 2007; 120:181-186.

34. Aquilante CL, Langaee TY, Lopez LM, Yarandi HN, Tromberg JS, Mohuczy D, Gaston L, Waddell CD, Chirico MJ and Johnson $\mathrm{JA}$. Influence of coagulation factor, vitamin $\mathrm{K}$ epoxide reductase complex subunit 1 , and cytochrome P450 2C9 gene polymorphisms on warfarin dose requirements. Clin Pharmacol Ther. 2006; 79(4):291-302.

35. Oner Ozgon $G$, Langaee TY, Feng $H$, Buyru $N$, Ulutin $T$, Hatemi AC, Siva A, Saip S, Johnson JA. VKORC1 and CYP2C9 polymorphisms are associated with warfarin dose requirements in Turkish patients. Eur J Clin Pharmacol. 2008; 64(9):889-94. 